\title{
A(s) natureza(s) da APA Macaé de Cima (Rio de Janeiro - Brasil): percepções, dilemas e conflitos
}

\section{The nature(s) of Environmental Protected Area Macaé de Cima (Rio de Janeiro - Brazil): perceptions, dilemmas and conflicts}

\section{Guilherme Hissa Villas Boas 1 (it) \\ Cristiane Passos de Mattos ${ }^{2}$ (10)}

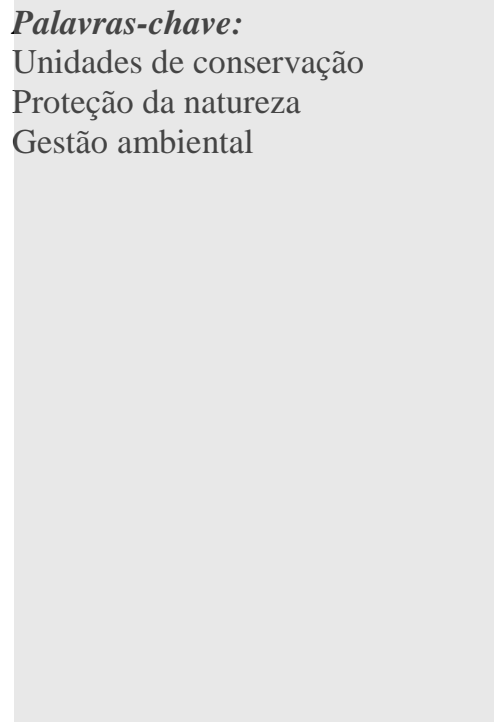

Keywords:

Protected areas

Nature protection, Environmental management.

\begin{abstract}
Resumo
A criação e gestão de unidades de conservação (UC) envolvem uma problemática complexa, uma vez que integra tensões e conflitos desde a institucionalização dessas áreas pelo estado até a implementação do ordenamento do território propriamente dito. Isso porque, muitas vezes, múltiplos interesses se contrapõem, subsistindo diferentes significados sobre a natureza que se quer proteger. Nesse contexto, o objetivo desse artigo foi elaborar uma (re)construção histórica da criação e implementação da APA Estadual Macaé de Cima e analisar qual(is) e como a(s) "natureza"(s) vem sendo protegida(s) nesta UC, localizada na região serrana do estado do Rio de Janeiro (Brasil). Para tal, foram sistematizadas informações relativas às ações de gestão e investigadas as diferentes percepções sobre natureza, dentre diferentes atores: gestores, conselheiros, proprietários e agricultores. A metodologia envolveu uma fase de campo com a realização de entrevistas, pautadas em procedimentos éticos, entre 2013 e 2019. Os resultados indicaram três visões de natureza que, por vezes, se mesclam entre si: a natureza contemplativa/bucólica, a natureza utilitária e a natureza científica.
\end{abstract}

\begin{abstract}
The creation and management of protected areas (PA) involve a complex problem, since it integrates tensions and conflicts originated by the institutionalization of these areas by the State and by the territorial planning and management. Often, this is because opposing interests between social groups, with different meanings about the nature and about what nature needs to be protected. In this context, the purpose of this article was to elaborate a historical (re)construction of the creation and implementation of the Macaé de Cima Environmental Protected Area and to analyze which one(s) and how the "nature"(s) has been protected. The methodology involved a literature review and interviews with managers, advisers, owners and farmers, between 2013 and 2019. The results indicate three visions of nature that sometimes mix with each other: the contemplative/bucolic nature, the utilitarian nature and the scientific nature.
\end{abstract}

\footnotetext{
${ }^{1}$ Universidade Federal do Rio de Janeiro (UFRJ), Departamento de Geografia, Rio de Janeiro, RJ, Brasil. guilherme.hissa@igeo.ufrj.br

${ }^{2}$ Centro Federal de Educação Tecnológica Celso Suckow da Fonseca (CEFET-RJ), Campus Nova Friburgo, Nova Friburgo, RJ, Brasil. cristiane.mattos@cefet-rj.br
} 


\section{INTRODUÇÃO}

Toda sociedade cria e transforma a maneira como percebe a natureza, sendo possível afirmar que seu significado condiciona e é condicionado pelas relações sociais, pela produção material e, portanto, pela própria cultura (MANTOVANI, 2009). O entendimento de natureza pode se diferir entre os grupos sociais que habitam e/ou interagem com o território (LEFF, 2009), tendo rebatimentos diretos no contexto da gestão de áreas protegidas.

Espaços protegidos ocorrem na história das sociedades muito antes da criação do Parque Nacional de Yellowstone (EUA) em 1872, considerado como o primeiro território delimitado para fins de proteção ambiental. Davenport e Rao (2002) apontam que em 550 a.C. no Império Persa, havia áreas de reserva de caça, enquanto em 400 a.C. na Índia já havia florestas com uso restrito devido a apelos religiosos.

Ainda que o entendimento contemporâneo sobre a proteção da natureza tenha origem em meados do século XIX, a constituição do paradigma ocidental moderno de natureza remonta ao século XII, quando foram instauradas reformas religiosas na Europa que culminaram na razão Iluminista (MANTOVANI, 2009). Sua consolidação desponta na revolução científica do século XVI, momento em que a natureza passa a não ser mais interpretada, prioritariamente, como uma manifestação da vontade divina (HOEFLE, 2016). Vale destacar que, dessa época até a égide das revoluções industriais, a natureza, passou a ser concebida como fonte inesgotável de riqueza, base para o progresso e desenvolvimento ilimitado da sociedade judaicocristã (RIBEIRO et al., 2012). Até o século XIX, o conceito de natureza foi sendo reduzido à dimensão físico-natural, ou seja, compreendido apenas como fauna, flora, terra, água, fogo e ar, excluindo-se o homem (HOEFLE, 2016). Na Europa do século XIX, a natureza vai passar a ser também percebida como local de contemplação, isolamento e reflexão, sendo valorizada em contraposição à cidade, que, imersa em expressivo crescimento populacional, começava a ser lócus de problemas como poluição e falta de saneamento (MANTOVANI, 2009).

É, nesse contexto, que ganham valor os relatos de viajantes e de escritores românticos ao tentarem descrever a natureza como o paraíso perdido ou o lugar da descoberta da alma humana. Os ambientes naturais são então apresentados como o local da inocência infantil, do refúgio e da intimidade, da beleza e do sublime. Surge a ideia de manutenção desses atributos através do isolamento de determinadas áreas. Isso ocorre principalmente nos Estados Unidos, em um período em que sua urbanização ocorria de forma acelerada e, sob a perspectiva do conceito de 'wilderness' (vida natural/selvagem), foram reservadas grandes áreas à expansão agrícola, à ação das mineradoras e à disposição das populações urbanas para recreação (DIEGUES, 2008).

Como decorrência, surgiram, no final do século XIX, duas correntes acerca da proteção ambiental: o preservacionismo e o conservacionismo. $\mathrm{Na}$ primeira, por muitos considerada o modelo americano de proteção, se defende a 'wilderness', por seu valor próprio, contra qualquer intrusão, mediante o isolamento de determinadas áreas. Já a corrente conservacionista, associada a um modelo europeu, pressupõe o bom uso dos recursos naturais (CASTRO JUNIOR et al., 2009) e tem se constituído como o caminho mais adequado para compatibilizar atividades humanas às necessidades de proteção da biodiversidade. Nas últimas décadas do século XX, o modelo preservacionista passou a ser amplamente utilizado nos países em desenvolvimento, como o Brasil. Críticos indicam que esse modelo resulta da conjugação de etnocentrismo e imperialismo, sendo eficiente somente em países desenvolvidos (CASTRO JUNIOR et al., 2009). Os argumentos se apoiam na remoção de populações tradicionais de seu território e a utilização da natureza enquanto mercadoria de exploração comercial através, principalmente, do seu uso contemplativo e turístico (BUSCHER et al., 2014).

No caso brasileiro, apesar das primeiras áreas protegidas terem sido criadas no início do século XX, somente em 1979, ocorreu um movimento do governo federal para sistematizá-las com a publicação do "Plano do Sistema de Unidades de Conservação do Brasil" (IBDF/FBCN, 1979). Atualizado em 1982, tinha como objetivo identificar as áreas mais importantes para conservação, além de propor um conjunto integrado de áreas protegidas. Somente em 1989, a pedido do governo federal, a Fundação Pró-Natureza (Funatura) redigiu um projeto de lei para criação de um sistema nacional de unidades de conservação. Este anteprojeto foi apresentado em 1992 ao Congresso Nacional e, após oito anos de amplos debates entre diversos setores da sociedade, foi então promulgada a lei 9.985 Sistema Nacional de Unidades de Conservação (BRASIL, 2000).

Apesar de diversas críticas, a publicação desta lei foi considerada um avanço nas políticas públicas no âmbito da proteção da natureza tendo em vista a elaboração de um documento legal que unificava os critérios para criação e gestão de diferentes tipologias e categorias de áreas protegidas que antes se encontravam dispersas entre vários instrumentos legais (MEDEIROS, 2006).

Passados vinte anos da publicação do SNUC, parece indispensável perguntar qual natureza se pretende proteger no Brasil, como tem sido feita essa proteção e para quem se destinam tais medidas. Essas indagações inspiraram a questão central desta pesquisa: analisar qual(is) e como a(s) "natureza(s)" 
vem sendo protegida(s) na Área de Proteção Ambiental Estadual de Macaé de Cima (APAMC), por meio da (re)construção histórica da criação e implementação dessa unidade de conservação (UC). Com esse horizonte, pretende-se também fomentar o debate acerca das estratégias legais em torno da proteção ambiental, especificamente considerando seus reflexos a partir de um estudo de caso.

Esta unidade de conservação, localizada na região serrana do estado do Rio de Janeiro (Brasil), entre os municípios de Nova Friburgo e Casimiro de Abreu, integra o grupo das unidades de uso sustentável e, portanto pressupõe a manutenção da população em seu território, o que inevitavelmente causa conflitos diante dos divergentes interesses em torno do uso de seus recursos naturais. Este trabalho tem como objetivo elaborar uma (re)construção histórica da criação e implementação da Área de Proteção Ambiental Estadual de Macaé de Cima, desde a colonização da área chegando à gestão atual do território, para compreender, por meio da interpretação das falas e das práticas dos diferentes atores no território, qual "natureza" que se pretende proteger, para quem se destina essa proteção e como ocorre esse processo.

\section{METODOLOGIA}

A metodologia envolveu: (1) levantamento de dados secundários (2) fase de campo, com realização de entrevistas dirigidas aos atores locais e (3) sistematização e análise do material pesquisado.

$\mathrm{Na}$ primeira etapa, a pesquisa bibliográfica envolveu um processo de busca da produção acadêmica disponível relacionada à área de estudo e à temática em questão. O plano de manejo da APAMC também foi alvo de análise com o propósito de se entender as estratégias por parte do órgão gestor, Instituto Estadual do Ambiente (INEA). Além disso, foram organizados dois mapas de uso e cobertura da terra a partir dos dados disponíveis no portal MapBiomas (2020) para verificar as alterações ao longo dos anos. Para o primeiro mapa selecionouse o ano de criação da primeira UC na área, enquanto o segundo tem como base as informações mais recentes disponíveis no portal.

A fase de campo caracterizou a segunda etapa metodológica sendo desenvolvida por meio da realização de 50 entrevistas entre 2013 e 2019, entre agricultores, proprietários de casas de veraneio, denominados adiante como sitiantes, gestores e conselheiros da UC, selecionados a partir de sua representatividade dentro dos grupos sociais. Por essa via, buscou-se levantar a compreensão acerca da natureza e das estratégias de proteção. O material obtido foi integralmente gravado e transcrito, tendo sido realizados os procedimentos éticos e a assinatura de Termos de Consentimento Livre e Esclarecido.

As entrevistas seguiram um roteiro pré-elaborado de acordo com o grupo social em questão, organizado de modo a alcançar, ao final, o assunto da unidade de conservação. Dessa forma, para os agricultores, o foco inicial das perguntas era seus entendimentos sobre os processos atuantes na paisagem, sua compreensão da dinâmica da natureza e estratégias de proteção dos recursos naturais. Com os sitiantes, gestores e conselheiros foram realizadas perguntas inicialmente focadas no processo e estratégias de proteção da natureza. A compreensão de natureza em si não fora o foco principal das perguntas, ou seja, não foram realizadas perguntas diretamente sobre o significado de natureza. Acreditamos que caso as perguntas tivessem sido realizadas dessa maneira, os entrevistados teriam oferecido respostas "prontas" que talvez não demonstrassem a sua compreensão subjetiva de natureza. Assim sendo, o levantamento desta informação fora elaborado a partir da etapa seguinte.

A terceira etapa investigativa foi conduzida pela técnica de Análise de Conteúdo. Tendo origem na década de 1940 nos Estados Unidos da América, esta técnica foi elaborada com o objetivo de ser aplicável às formas de comunicação, com priorização daquelas construídas através de um código linguístico, a fim de analisar os conteúdos ditos e "não ditos" das mensagens (BARDIN, 2011). Assim, os significados da natureza puderam ser identificados, agrupados conforme semelhanças/diferenças, interpretados e analisados.

\section{RESULTADOS}

\section{Um pouco de história}

A história do alto curso da bacia do rio Macaé se difere de outras regiões do estado do Rio de Janeiro, por conta de seu relevo íngreme e acidentado da Serra do Mar (figura 1), da densa floresta tropical úmida e da presença de tribos indígenas hostis e quilombos (MAYER, 2003). No século XIX, a Serra do Mar servia ainda como rota para contrabandistas de ouro vindo de Minas Gerais que fugiam da tributação da coroa. 
Figura 1. Mapa de localização da APAMC

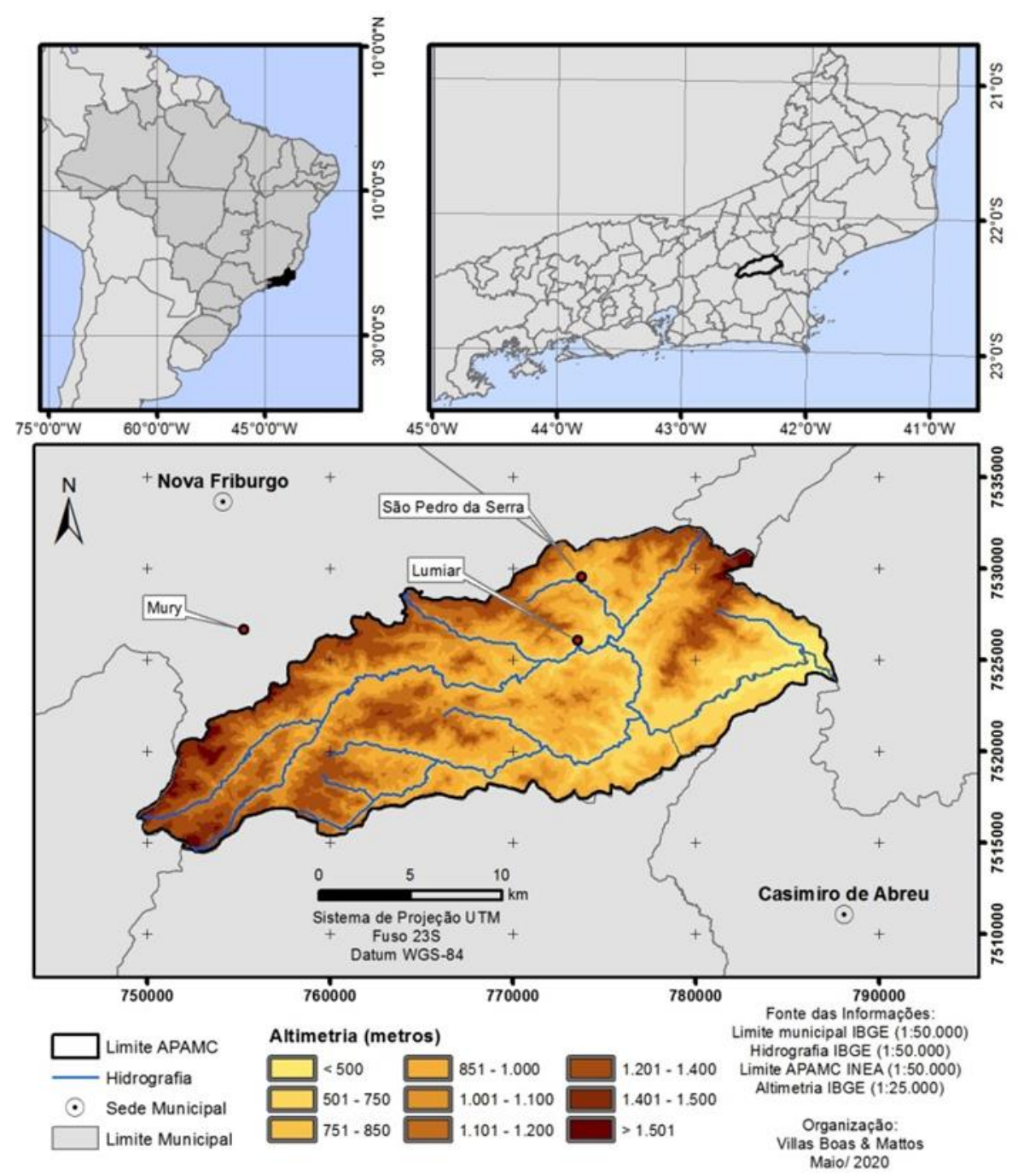

Fonte: INEA (2014). Org: os autores, 2020.

Em 1818, foi formulado o projeto de imigração suíça para as terras da Fazenda Morro Queimado, que hoje correspondem ao centro do município de Nova Friburgo. O projeto previa a vinda de 2000 imigrantes entre agricultores, carpinteiros, marceneiros, ferradores, curtidores, alfaiates, tecelões e oleiros e a distribuição de lotes de terras fundamentada na pequena propriedade, na isenção de impostos, no pagamento da viagem e em subsídios monetários aos colonos (MAYER, 2003). A produção rural era incentivada, com finalidade de promover a autossuficiência e integração campocidade a nível local (NICOULIN, 1995).
A fixação se deu em três eixos ao longo dos vales fluviais adjacentes à área: rio Grande, rio Cônego e o rio Macaé. Já em 1821, inúmeros lotes destinados aos colonos se mostraram improdutivos pela localização nas íngremes escarpas da região, pelos solos rasos e pedregosos e pela densa cobertura florestal (figura 2). Em 1824, ocorre a migração de colonos alemães para Nova Friburgo para fortalecer a dinâmica da então colônia suíça. Esses também receberam terras no vale do rio Macaé, porém não se pode apontar com exatidão quantos se fixaram nesse eixo leste da colonização (MAYER, 2003). 
Figura 2: Atividades agrícolas em vertentes íngremes em primeiro plano e ao fundo a cobertura florestal e afloramentos rochosos.

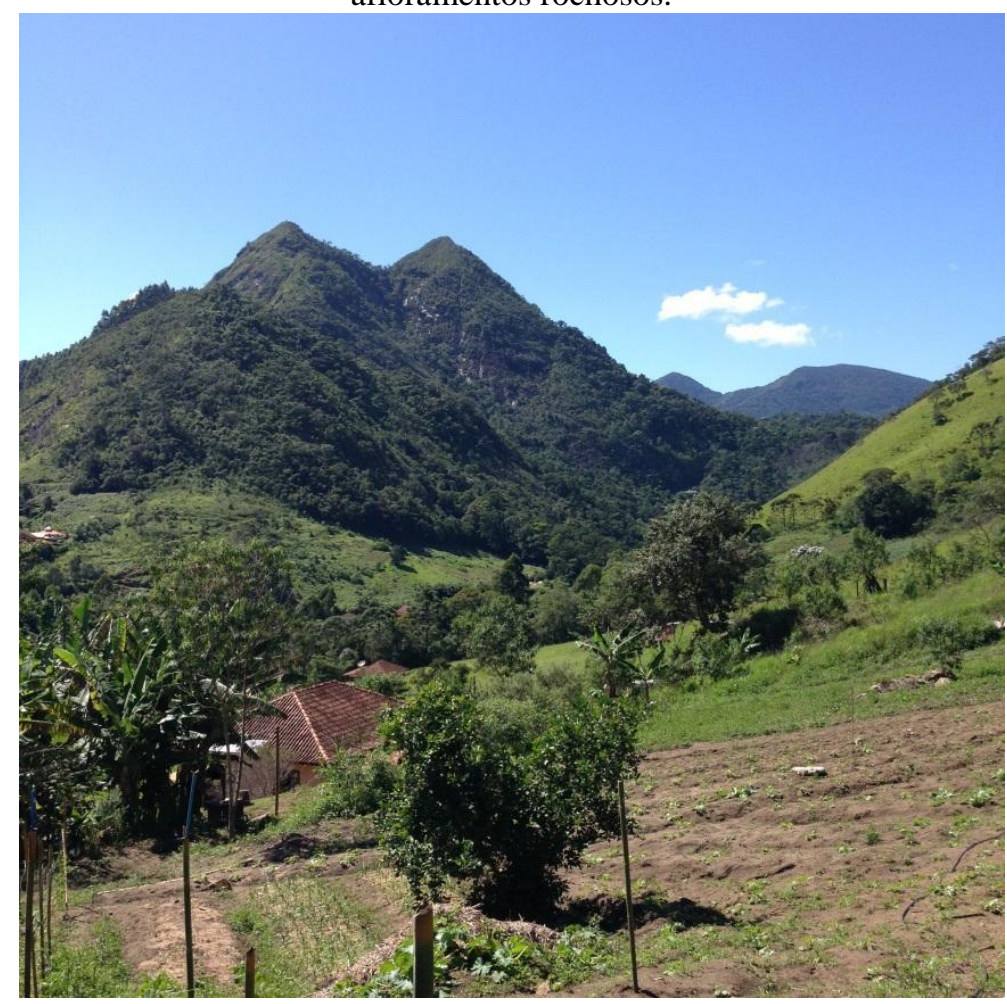

Fonte: os autores, 2020.

Ao contrário do que esperava o governo imperial, os colonos utilizaram técnicas tradicionais brasileiras, como o pousio e a queimada para a derrubada da vegetação e tratamento dos solos. Em função de estarem distanciados geograficamente da administração da colônia, teriam perdido traços culturais europeus de origem, recorrendo aos recursos florestais para assegurar sua saúde e para a construção de moradias (MAYER, 2003).

Nova Friburgo manteve características rurais até o início do século XX, quando em 1910 foram criadas indústrias do ramo têxtil. A partir de então, a cidade passou a ser ligada por trem à capital e a receber o fornecimento de energia (ARAÚJO, 2003). Apesar de fazerem parte deste município, as terras montanhosas da APAMC perduraram com uma dinâmica agrícola com um grau de isolamento geográfico até 1960 , já que no final da década de 1950, por iniciativa dos moradores, foi aberta a estrada que liga Mury à Lumiar, refazendo o antigo caminho das tropas (VILLAS BOAS, 2017). Este fato possibilitou a chegada do primeiro transporte coletivo que ligou Lumiar à sede do município no início dos anos 1960 em uma única viagem diária.

Foi a partir dos anos 1970 que as características agrícolas iniciais teriam sido modificadas com o uso intensivo de insumos agrícolas e com a subordinação à economia de mercado. Neste período, observou-se também a ascensão do turismo como uma prática social na região (AMADOR, 1997). Os turistas pioneiros ou aventureiros, dispostos a enfrentar acessos precários e falta de energia elétrica, buscavam isolamento dos centros urbanos (REGO, 1988). Na década de 1980, se consolida a dinâmica de pluriatividade que passou a caracterizar a região. O asfaltamento da Mury-Lumiar ocorreu somente em 1982 e a eletricidade chegou em 1985. Nesta década, a região se configurava como uma nova fronteira para o turismo estadual, tendo a natureza como atrativo principal.

$\mathrm{Na}$ década de 1990, uma mudança no perfil do turista ocorre: se antes os "hippies" dormiam em barracas às margens dos rios, agora os "de fora" passam a adquirir terrenos na região para a construção de casas de segunda residência, buscando uma experiência bucólica (AMADOR, 1997). A chegada da rede de telefonia, o asfaltamento da rodovia Lumiar-São Pedro da Serra em 1995 e o crescimento do turismo acabam por induzir o aumento do preço da terra, o que teria motivado agricultores a abandonarem o lugar em que viviam para se tornar caseiros, em áreas que antes lhes pertenciam (MAYER, 2011).

Já se podia observar, ao final dos anos 1990, certa divisão entre o perfil dos proprietários de terras de acordo com os vales fluviais. Enquanto os vales mais ao sul e oeste da bacia: Macaé, rio das Flores e rio Bonito já se observava uma expressiva presença daqueles "de fora", os vales mais ao norte e leste da bacia: rio Boa Esperança e rio São Pedro ainda mantinham os descendentes de europeus e as atividades agrícolas (figura 3 ). 
Figura 3 - Mapa das localidades, principais canais fluviais e vias de acesso da APAMC.

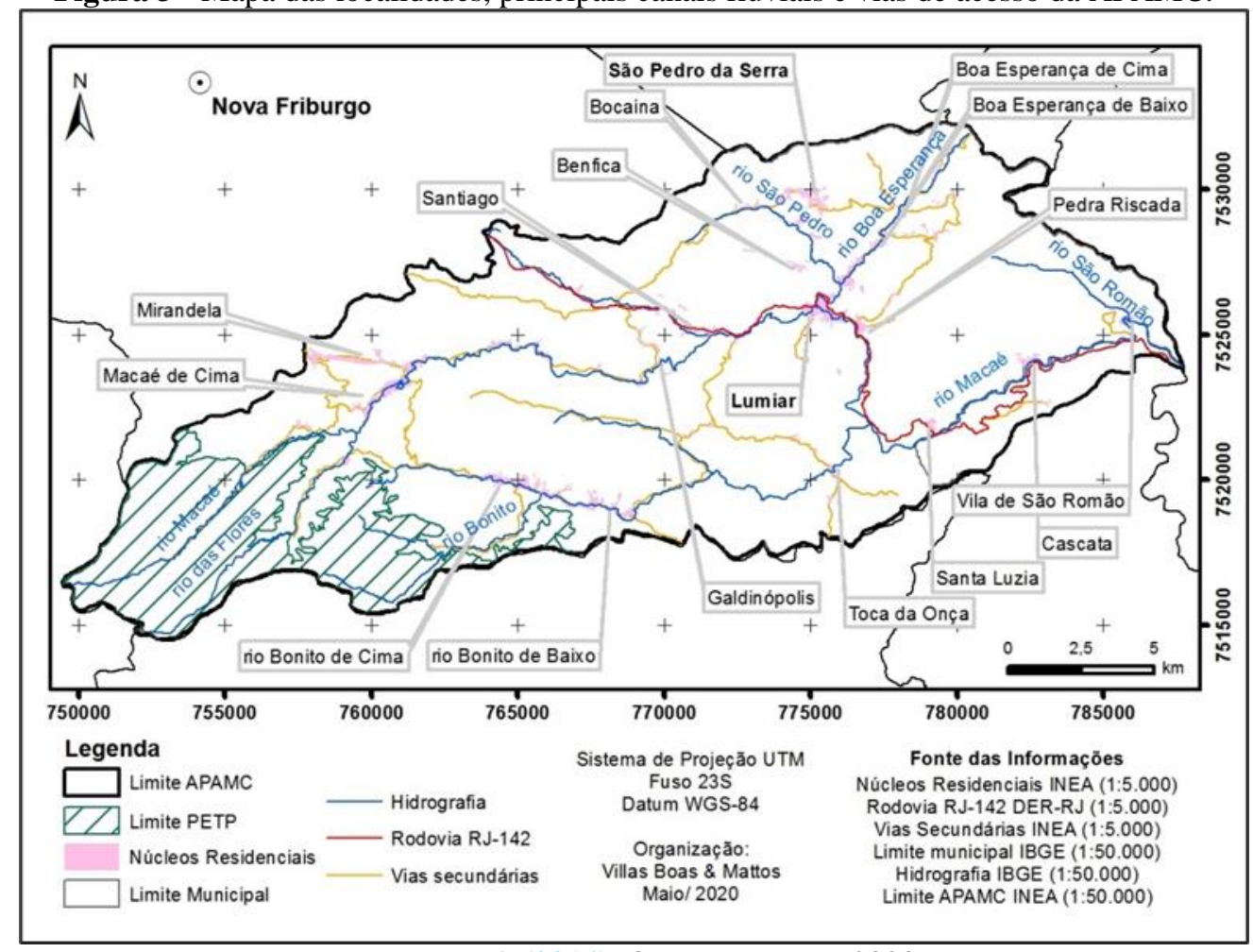

Fonte: INEA (2014). Org.: os autores, 2020.

\section{A criação da APAMC}

A região da APAMC se turistificou ainda na década de 1970, por meio da leitura da área como um "paraíso perdido" por atores que residiam em centros urbanos (REGO, 2009). Esse ideário de "paraíso perdido" associava-se à percepção da natureza como bucólica e misteriosa, uma natureza fascinante (flower power). Além disso, a difusão da notícia de um fragmento preservado de Mata Atlântica também atraiu pesquisadores do Instituto do Jardim Botânico do Rio de Janeiro (IJBRJ) o que resultou em uma expressiva literatura acadêmica de cunho florístico e taxonômico, ilustrada pelos cinquenta artigos publicados entre 1977 e 1998. Esse contexto se traduziu na construção de laços de proximidade entre os pesquisadores do IJBRJ e alguns proprietários de sítios em Macaé de Cima, o que, anos mais tarde, culminou em um movimento que impulsionou a institucionalização, em 1984, da Sociedade Macaé de Cima, hoje denominada Associação Macaé de Cima (MATTOS, 2018).

Respaldada pelas pesquisas científicas, a Sociedade Macaé de Cima solicita ao poder público municipal a criação de uma unidade de conservação no alto curso do Rio Macaé. Assim, em 1989, o IJBRJ encaminhou um pedido à prefeitura de Nova Friburgo voltado à criação de uma área protegida. Então, em janeiro de 1990, o Decreto Municipal no. 156 institui a Reserva Ecológica de Macaé de Cima (REMC) com 70km2, cerca de $1 / 5$ da extensão atual da APAMC. Nesta mesma época, fora criada a Área de Proteção Ambiental Municipal do Rio Bonito (APARB), também pela prefeitura de Nova Friburgo. Ainda que as duas Unidades de Conservação, sob a gestão do IJBRJ, nunca tenham saído do papel, originalmente a REMC proibia diversas práticas cotidianas como a passagem de ônibus pelo seu interior, o abastecimento de gás nas residências, entre outras.

A REMC perdurou como uma área protegida municipal até o ano de 1997, ano em que foram revogados tanto o decreto de criação quanto o plano de zoneamento da área (INEA, 2014). Tal revogação foi resultante de um cenário de disputas relacionado à instalação de um empreendimento turístico, que previa a construção de cinquenta unidades habitacionais, em desacordo com o decreto de criação da REMC (MENDES, 2010).

Em 1999, a Sociedade Macaé de Cima provoca novamente o poder público, mas, desta vez, direciona esforços à Fundação Estadual de Engenharia do Meio Ambiente (FEEMA) a fim de criar uma unidade de conservação na área da REMC e da APARB. Por meio dessa e outras ações, pode-se afirmar que seu papel foi relevante para a proteção ambiental no alto curso da bacia do rio Macaé (MATTOS, 2018). No pano de fundo, nos anos subsequentes, parece que o interesse da referida associação em criar uma unidade de uso sustentável estava associado à defesa de suas terras, tendo em vista que não se desejava uma regularização fundiária característica de unidades de proteção integral (REGO, 2009). 
Como resposta a essas iniciativas, a APAMC foi criada por meio do Decreto Estadual No. 29.213, de 14 de setembro de 2001 (RIO DE JANEIRO, 2001). Esse momento foi interpretado por muitos agricultores e outros atores sociais locais, como uma vitória dos grupos vinculados aos interesses de sitiantes, turistas, ambientalistas, enfim os "de fora" (REGO, 2009).

\section{Do início da gestão aos dias de hoje}

Um ano após a criação da APAMC fora criado o Parque Estadual dos Três Picos (PETP) com uma área sobreposta à APA. Até 2005, a APAMC permaneceu "na gaveta" e nenhuma ação pública fora realizada. Por conta disso, muitos moradores desconheciam a existência da unidade neste período. A partir deste ano, a FEEMA iniciou a gestão da unidade, alocando um gestor para as nove unidades de uso sustentável geridas pelo órgão. A principal prática da gestão envolvia investidas de campo, temporalmente espaçadas, para fiscalizar práticas agrícolas proibidas, e aplicação de multas, com base no (extinto) código florestal.

No final de 2004, a FEEMA criou o Conselho Consultivo da APA Macaé de Cima (CONAPAMC) e sem ampla consulta pública, indicou para compô-lo 20 instituições. Nos anos subsequentes, as reuniões do conselho eram compostas prioritariamente por representantes de órgãos públicos e pelos proprietários "estrangeiros" e sitiantes, como reflexo, também, do meio de comunicação escolhido para as convocações - mensagem eletrônica (email), uma vez que grande parte da população local não tinha acesso a esta tecnologia.

Cabe destacar que o primeiro instrumento de gestão da APAMC se baseou no seu próprio decreto de criação, já que nele estavam previstas as atividades socioeconômicas e as práticas de manejo a serem fiscalizadas pelo órgão gestor. Sendo assim, a caça, o desmatamento em áreas de matas ciliares, o parcelamento do solo voltado à urbanização, a abertura de logradouros, as queimadas, a extração de madeira e a terraplanagem tornaram-se foco prioritário das ações da gestão nesse período, atividades estas já proibidas através de outros instrumentos legais. Diversos agricultores, grande parte com pouca formação acadêmica, relataram, nas entrevistas, não só a dificuldade que tinham para saber as práticas aceitáveis e as áreas onde se podia cultivar, como também o uso de truculência por parte dos funcionários públicos.

O ambiente social, nestes primeiros anos após a criação da UC, se caracterizou por um contexto de embates e conflitos entre os agricultores e demais atores locais e o órgão gestor (REGO, 2009). Ainda que este tipo de conflito seja recorrente em outras áreas do Brasil, em que o imaginário dos agricultores se difere completamente da leitura do meio ambiente pelo órgão gestor (LASCHEFSKI et al., 2012), a origem desses conflitos, na APAMC, parece ter sido a desinformação e a incipiente comunicação entre os órgãos públicos e a população local, (CARNEIRO et al., 2010). Esses conflitos se concretizaram, inclusive, porque os agricultores percebiam a equipe da gestão da APAMC como a origem do processo de coerção às suas práticas tradicionais de manejo da terra (TEIXEIRA, 2009). E, nessa conjuntura, podese afirmar que esse teria sido o marco referencial dos conflitos entre agricultores familiares e os grupos de interesses vinculados à gestão da APAMC e/ou aos movimentos ambientalistas, contexto esse que se mantém até os dias atuais.

Com objetivo de (re)construir o histórico das ações de gestão do território é importante destacar que em janeiro de 2007, o Instituto Estadual de Florestas (IEF) assume a cogestão de todas as UCs da FEEMA e em outubro do mesmo ano o primeiro gestor exclusivo da APAMC assume o cargo. Sendo um morador da região, esta escolha parecia ter como objetivo tentar melhorar o clima entre a comunidade e órgão gestor. A unidade passou a dispor de uma viatura, um aparelho de posicionamento global (GPS) e um inclinômetro, a partir de 2008, cujo foco aparentou ser basicamente a continuidade das práticas antigas: fiscalização e aplicação de multas.

Quando em 2007, o Instituto Estadual do Ambiente (INEA) fora criado, a APAMC passou a ser gerida pela Gerência de Unidades de Uso Sustentável (GEUSO). A partir desse momento, teve início a reestruturação do CONAPAMC, uma vez que passou-se de 20 para 42 , no total de conselheiros $\mathrm{e}$, no que concerne às associações de agricultores $\mathrm{e}$ sitiantes, o crescimento foi de 8 para 20 cadeiras de representação. Ainda que a entrada de novos membros possa ter possibilitado um ambiente diferenciado, muitos conselheiros relataram que uma parcela considerável das instituições era de fachada, ou seja, não tinha representatividade, pois haviam sido criadas somente para integrarem o conselho.

Neste mesmo ano e, no ano seguinte, duas ações foram protocoladas na Assembleia Legislativa do Estado do Rio de Janeiro (ALERJ) por associações de moradores locais solicitando a revogação da criação da APAMC. Apesar de não utilizar o termo "plano de manejo", uma das cartas protocolada deixava clara a carência do mesmo e as orientações do estado com relação às práticas aceitáveis na região. As associações alegavam também que as atividades agrícolas desenvolvidas em áreas de APP, que vinham sendo alvo de fiscalização e multas, já eram praticadas desde os primeiros colonos e se justificavam por conta das características ambientais, mas que a região nunca estivera "tão verde". Estava criada aí a dicotomia em torno da "natureza" da APA, de um lado o grupo de "estrangeiros" interessados na manutenção da cobertura florestal e de outro os agricultores clamando por áreas agricultáveis e pela manutenção de práticas tradicionais. 
Ressalta-se que a lei estadual $\mathrm{n}^{\circ} 2.049$ (RIO DE JANEIRO, 1992) que proíbe o uso de fogo em diversas áreas, inclusive em áreas de preservação permanente (APP), acabou afetando os pequenos agricultores de todo estado, ainda que seu propósito inicial tenha sido o de restringir o uso do fogo nos canaviais do norte fluminense. Aplicando-se esta lei, na APAMC, praticamente não restaria nenhuma área disponível para manejo tradicional agrícola.

Os gestores entrevistados apontam que um dos motivos de maior recorrência de denúncias de crimes ambientais era, e ainda é, a prática de queimada associada ao pousio. Nesta prática, os agricultores abandonam a terra para que ela possa "descansar". Durante os anos seguintes, ocorre a regeneração da floresta e então é feita a derrubada do material lenhoso e a utilização do fogo para limpar a área e fertilizar o solo. Ainda que esse sistema agrícola possa parecer primitivo, ineficiente e ambientalmente inadequado, sob circunstâncias apropriadas, é capaz de ser altamente produtivo em termos de energia e relativamente neutro nos seus efeitos ecológicos (OLIVEIRA, 2007).

Como se pode imaginar, tanto a clareira aberta pelos agricultores como o momento da combustão não constituíam uma cena bem vista pelos "de fora", desfazendo aquela imagem de uma natureza bucólica e pura, conflito ilustrado por um dos conselheiros do CONPAMC:

"conflito de interesses ... conflito do agricultor que precisa fazer um pequeno desmatamento pra cultivar e a visão preservacionista de ... da natureza intocada por parte de pessoas que vem da cidade ... éh ... esse conflito de visão".

Nos anos subsequentes, o cenário geral de tensão fora abrandado já que iniciativas populares voltadas à revogação do decreto de criação da APAMC não tiveram atuação expressiva. Além disso, em 2009, a GEUSO submete três projetos para captação de recursos junto à Câmara de Compensação Ambiental do Estado do Rio de Janeiro, e somente o terceiro, que trazia o PETP como beneficiário, fora aprovado. Isto porque a APAMC fora considerada como uma área prioritária para a preservação do PETP por estar localizada na sua zona de amortecimento e não possuir, até então, uma sede e o plano de manejo.

Reconhecendo que os planos de manejo em APAs constituem "ferramentas de gestão essenciais" (BERNARDI et al., 2019), a elaboração desse instrumento na APAMC, iniciada em 2010, envolveu inúmeras estratégias participativas, tendo sido, para moradores e sitiantes, um meio para o fortalecimento da UC, e tendo representado um aperfeiçoamento metodológico para o órgão gestor. As oficinas, ou reuniões comunitárias, foram realizadas aos finais de semana em todas as aglomerações urbanas da APA. Publicado em 2014, o documento aborda a UC como um meio para a melhoria da qualidade de vida da população residente. Dentre as principais ações previstas, nesse instrumento de gestão, estão aquelas voltadas à educação ambiental, à fiscalização, ao fomento de pesquisas e à prática de um turismo responsável.

Apesar das iniciativas participativas realizadas durante a construção do plano de manejo e a reestruturação do CONAPAMC, alguns quadros de tensão, decorrentes principalmente de ações de fiscalização, parecem ter levado o órgão a substituir, em 2014, o então gestor. Sua substituta, também moradora da região e servidora do município, quando se viu diante de um ambiente conturbado e uma relação desgastada entre a população autóctone e o órgão gestor, permaneceu somente dois meses à frente da UC. Em um cenário de tensão, fora designado um novo profissional, residente da cidade do Rio de Janeiro. Este adotou uma postura diferente: optou por estar presente nas reuniões das associações locais criando um ambiente de maior diálogo. Além disso, manteve flexibilidade em relação às atividades de fiscalização na medida em que foram sendo pactuadas novas condutas. Exonerado em 2016 pelo INEA, sem justificativa fornecida ao conselho, foi o único gestor a receber menção do conselho contrária à sua exoneração.

Entre março de 2016 e início de 2018, esteve à frente da gestão um profissional que tinha permanecido, anteriormente, por quase uma década, à frente do PETP, tendo um perfil "mais preservacionista". No ano de 2018, um gestor, com vínculo pregresso à secretaria municipal de meio ambiente de Nova Friburgo, respondeu pela unidade, tendo sido considerado uma indicação política para o cargo. Desde 2019, um analista ambiental concursado, morador da região e que já integrava a equipe da UC desde 2015, passou a responder pela chefia da unidade. Foi possível perceber, pela análise das entrevistas, que, dada a incipiente atuação do poder público municipal em toda APAMC, foi construída uma representação do chefe da unidade como um ator relevante na política local.

$\mathrm{Na}$ última gestão, houve a flexibilização em relação à fiscalização do pousio, sendo permitido o manejo mediante cadastro. Mas, segundo os agricultores, os processos têm sido morosos. Há de se destacar também que alguns deles solicitam autorização para supressão de vegetação considerando períodos de plantio sem prazo hábil para o órgão emitir o parecer, enquanto outros fazem a supressão $\operatorname{logo}$ após a abertura do processo inclusive sem aguardar a vistoria.

Os mapas de uso e cobertura da terra (figura 4) demonstram a redução da área dedicada à agricultura, o crescimento da cobertura florestal e a expansão da área urbana. Se em 1990, ano de criação da REMC, havia $80 \%$ de cobertura florestal, em 2018 esse valor cresceu para $82 \%$, correspondendo a um crescimento de 600 hectares. Atribui-se a esse fato o resultado conjugado de anos de fiscalização, 
da delimitação das terras agricultáveis pelo plano de manejo, estas baseadas em imagens de satélite de 2010, onde as áreas cobertas por florestas passaram a ser dedicadas à preservação, o abandono da prática de pousio e a adoção de técnicas modernas na agricultura, como o uso de defensivos e adubação química, e principalmente pela aquisição de terrenos pelos sitiantes, que sem interesse pela agricultura permitem a recolonização da cobertura florestal (figura 5).

Figura 4 - Mapa de uso e cobertura da APAMC entre 1990 e 2018.
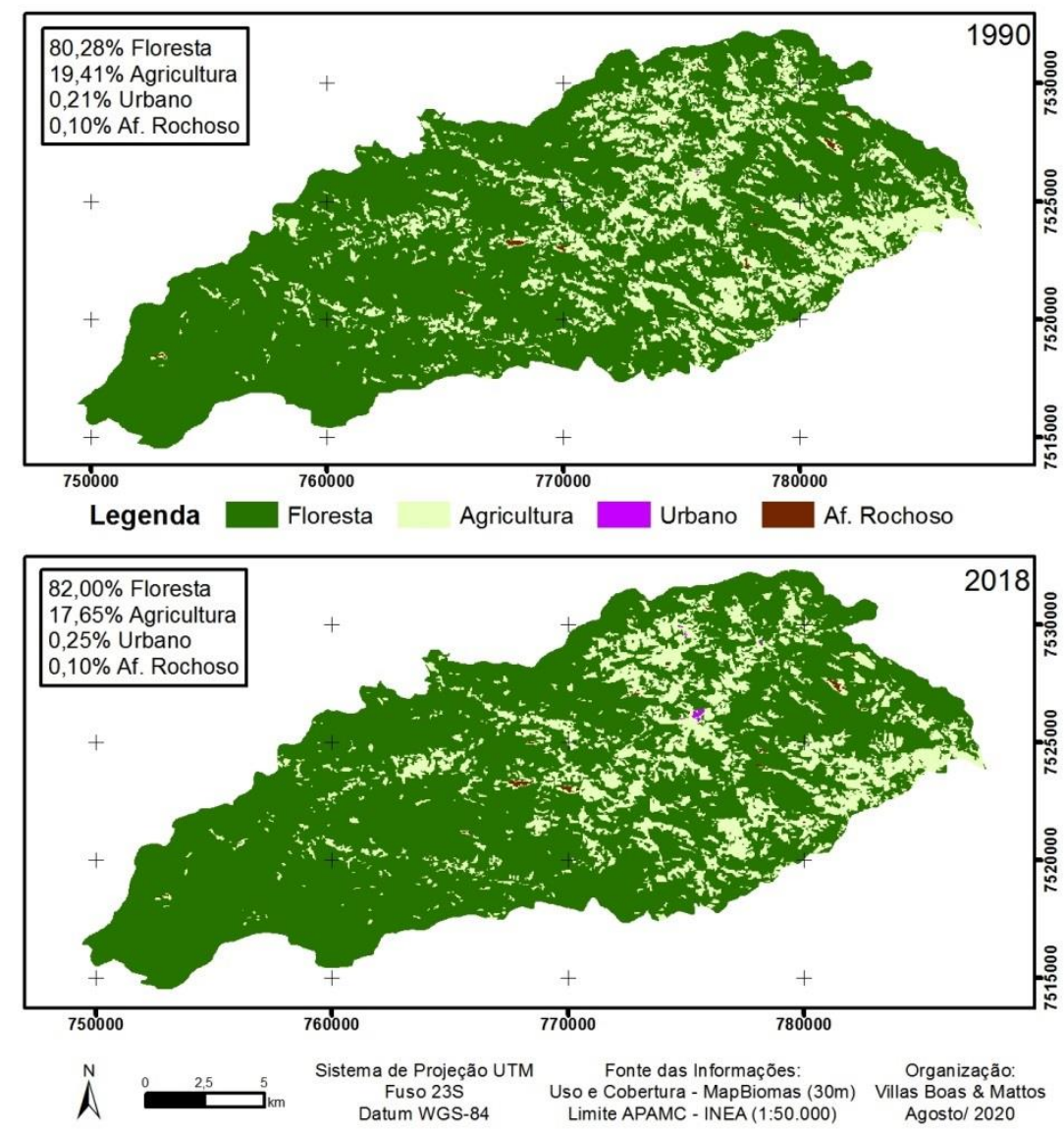

Fonte: MapBiomas (2020). Org.: os autores, 2020.

Figura 5: Casa de veraneio em fundo de vale e a vertente destinada à regeneração vegetacional.

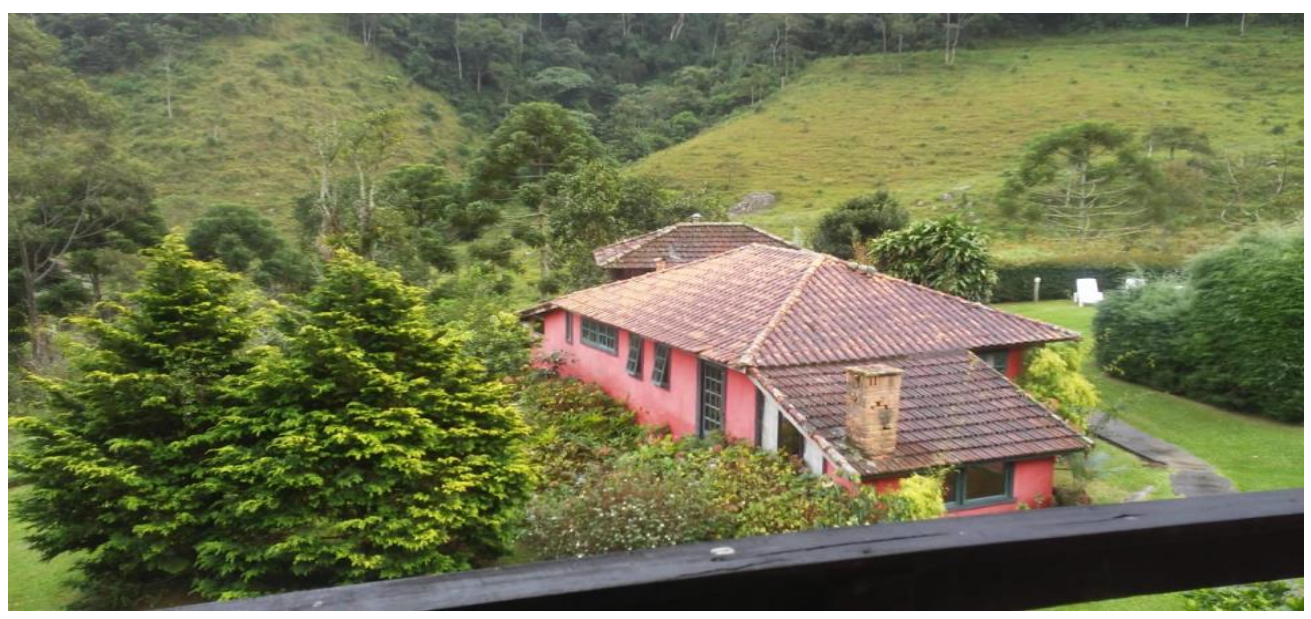

Fonte: os autores, 2020. 
Os agricultores relataram que se reconhecem como guardiões da natureza, por meio de laços afetivos estabelecidos, não apenas como usuários de recursos naturais (MATTOS, 2018). Este fato é, inclusive, apontado no plano de manejo. Contudo este documento norteador da gestão, pautado em uma visão cientificista, ainda descreve, e, portanto, entende, os elementos da natureza de forma segmentada: clima, relevo, solo, hidrografia, fauna, flora, etc. Ainda que, aos olhos de um acadêmico, o plano de manejo elabore um boa descrição dos elementos constituintes da paisagem, reforçando inclusive os múltiplos interesses pelos recursos naturais, o entendimento de natureza ainda se dá como algo externo à sociedade, corroborando a dicotomia da ciência moderna que coloca homem como "não-natural" e a natureza como "nãohumana" (VILLAS BOAS, 2017).

Por fim, ao longo das entrevistas foram identificados, dentre os atores sociais, três principais entendimentos sobre natureza. Natureza Contemplativa e Bucólica: a natureza percebida por meio de sua beleza cênica, de seu aspecto transcendental e bucólico e, por isso, como elemento motivador/atrativo do turismo; uma natureza que está fora do sujeito, "externa" ao seu cotidiano, uma natureza que deve ser essencialmente preservada; Natureza Utilitária: intrinsecamente associada ao cotidiano, ou seja, entendida como parte da engrenagem da vida, com a qual o sujeito se relaciona diretamente. Esta leitura foi compartilhada principalmente pelos agricultores, segundo a qual é necessária sua proteção e seu uso prescinde de uma relação cotidiana; Natureza Científica: se mescla à ideia de um mero banco de recursos naturais, ou seja, uma natureza científica, percebida também como meio para conservação estratégica e manutenção de serviços ecossistêmicos (figura 6). Apesar do esforço de sistematização, não se pode negligenciar que alguns significados de natureza mesclam aspectos de dois ou mais entendimentos mapeados, não sendo, portanto, excludentes.

Figura 6 - Modelo esquemático dos diferentes entendimentos sobre natureza, suas interseções e exemplos de narrativas que os ilustram.

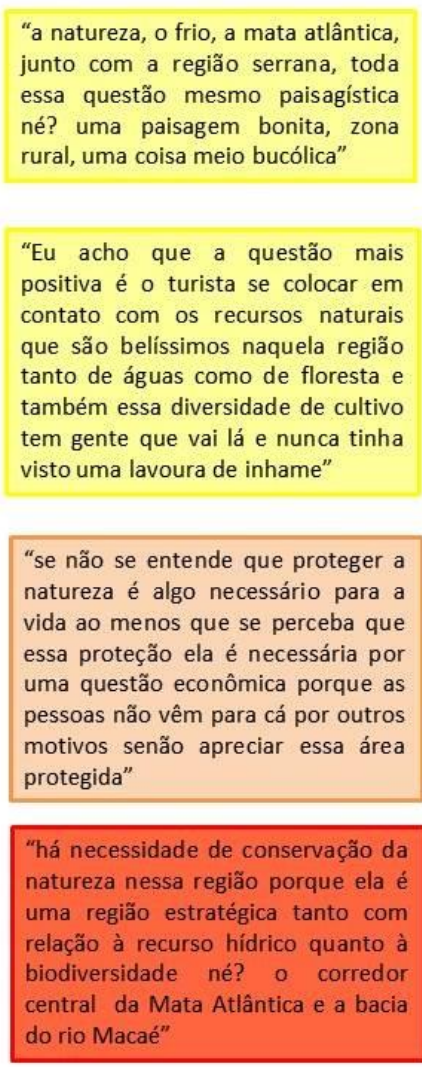

"Eu acho que a questão mais positiva é o turista se colocar em contato com os recursos naturais que são belíssimos naquela região também essa diversidade de cultivo tem gente que vai lá e nunca tinha visto uma lavoura de inhame"

"se não se entende que proteger a menos que se perceba que ssa proteção ela é necessária por protivos señ̃o apreciar essa área pregida

"há necessidade de conservaç̃o da natureza nessa região porque ela é relacão à recurso hídrico quanto $i$ tanto con biodiversidade né? o corredor do rio Macaé"

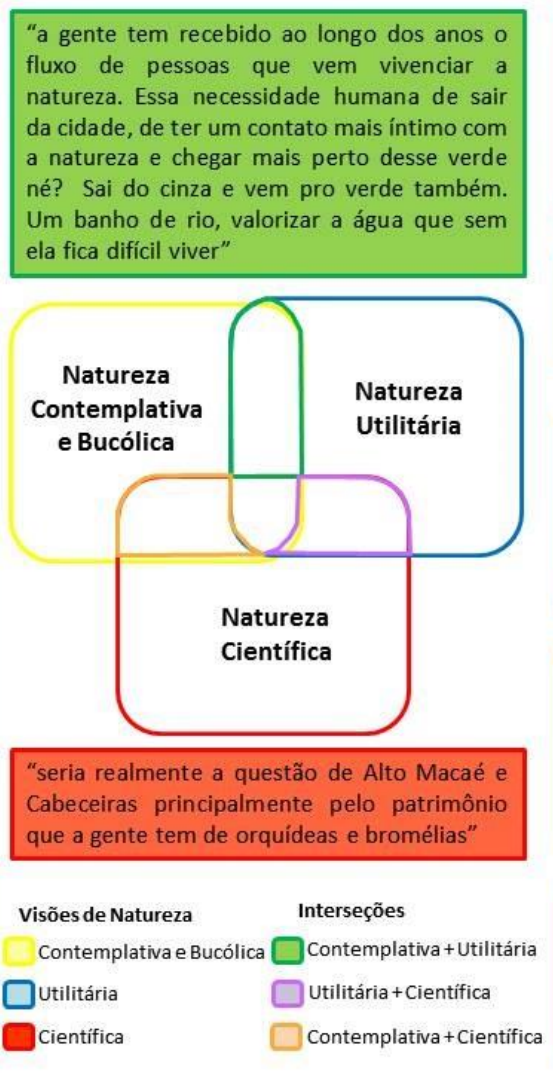

"meu avô preservava uma mata, não deixava ninguém derrubar e mata tá lá até hoje. Eu nunca vou ter vontade de derrubar ela porque é uma mata bonita, eu gosto"

“nós estamos dentro da natureza e a natureza ela está aqui para todos viverem dela"

\begin{tabular}{|c|}
\hline $\begin{array}{l}\text { "e só ficou na lavoura quem } \\
\text { amava de verdade, aquele cara } \\
\text { que não amava a planta, que não } \\
\text { conversa com a planta, que não } \\
\text { conversa com a natureza, ele } \\
\text { simplesmente ele saiu" }\end{array}$ \\
\hline $\begin{array}{l}\text { "eu converso com a natureza, eu } \\
\text { estudo a natureza, eu tenho dias } \\
\text { em que eu vejo coisas incríveis } \\
\text { que ela oferece para a gente } \\
\text { então cada vez eu respeito ela } \\
\text { mais" }\end{array}$ \\
\hline
\end{tabular}

"natureza é algo necessário para a
vida ao menos que se perceba
que essa proteção ela é
necessária por uma questão
econômica"

Fonte: os autores, 2020.

\section{CONCLUSÕES}

Considerando a discussão sobre como se aplica o uso sustentável previsto no SNUC à luz das práticas pretéritas e atuais, por meio do estudo da APAMC, é possível afirmar a existência de um conflito dicotômico em torno do interesse pela natureza materializado em dois principais grupos sociais: os "de fora" e os "de dentro". O entendimento e o uso 
dado à natureza ocorrem de formas distintas, materializadas principalmente por duas atividades sociais: o turismo e a agricultura. Enquanto os atores interessados no turismo enxergam a natureza como um cenário (quase) estático, senso comum de paisagem tal qual um quadro pintado, alvo de contemplação e um ambiente idílico, os agricultores a veem como substrato ou o lócus de suas atividades, o conceito geográfico de paisagem como um sistema dinâmico e integrado. Ainda que estes dois grupos tenham o mesmo objetivo - a manutenção da qualidade ambiental - a natureza é percebida ora como um recurso a ser explorado indiretamente, pela contemplação, a visitação a um ambiente rústico e oposto ao urbano, ora como um recurso a ser explorado de forma direta, sendo fonte de nutrientes e aeração para o solo, por exemplo.

Diante disto, são compreensíveis as estratégias para a proteção da natureza na APAMC: enquanto o grupo dos "de fora" prega o isolamento dos recursos e manutenção dos atributos estéticos, os "de dentro" priorizam seu uso, denotando assim a necessidade da criação de um modelo de UC socialmente inclusivo. $\mathrm{O}$ argumento pela manutenção da floresta, travestido pela sua importância no regime hidrológico, é uma estratégia que atende a dois propósitos: a perpetuação da paisagem idealizada das áreas não urbanas e a conservação dos principais atrativos turísticos naturais: as cachoeiras, praias e poços fluviais. Paralelamente a isto, a prática de pousio e a consequente "movimentação" da cobertura florestal vêm sendo abandonadas a partir da delimitação das áreas agricultáveis e das áreas a serem preservadas. Isto é, ainda que a APAMC integre as unidades de uso sustentável, na prática, foram criadas áreas "intocáveis", perpetuando "ilhas" do modelo preservacionista em meio à atividade agrícola. A combinação entre as ações de proteção ambiental com o processo de modernização da agricultura tem levado os agricultores a aderirem ao uso de insumos químicos como fertilizantes, inseticidas e pesticidas, tornando suas práticas ainda mais questionáveis no que tange a manutenção da qualidade ambiental.

Outro fator a ser levantado é a genérica definição de Área de Proteção Ambiental, diferentemente das outras categorias do SNUC. O artigo $15^{\circ}$ da lei $9.985 / 2000$ e o decreto $4.340 / 2000$ praticamente atribuem ao plano de manejo a responsabilidade e as orientações de "o que" e "como" gerir esta categoria. Em certa medida, estes instrumentos legais possibilitam a criação de mais áreas protegidas sob esta categoria, contudo, ao não delimitarem bem seu propósito, dedicam ao órgão gestor a atribuição de definir interesses e modelos dos elementos a serem protegidos. Mais do isso, quando a lei aponta que a APA é "uma área com certo grau de ocupação humana dotada de atributos [...] importantes para qualidade de vida", acaba tornando ambíguo o entendimento das ameaças aos seus objetivos: "proteger a diversidade biológica, disciplinar o processo de ocupação e assegurar a sustentabilidade do uso dos recursos naturais" (BRASIL, 2000).

Cabe então a pergunta "proteger de quem?" tendo em vista ser admitida ocupação pregressa. Entendemos que os grupos que ali se encontravam não devam ser considerados como ameaças, considerando que foram justamente eles quem mantiveram a qualidade ambiental da área, atributo capaz de proporcionar a criação da UC. Outra pergunta, não menos importante, ainda com base nos instrumentos legais, seria "proteger para quem?". Neste caso, podemos observar que, tanto o SNUC como os processos de criação e de gestão das áreas protegidas, são quase que exclusivamente pautados na visão cientificista de natureza, sem levar em consideração o conhecimento empírico dos heterogêneos grupos sociais que habitam seus territórios. Aliado a isto observa-se que a presença do estado materializado na unidade de conservação conduz parte da população, com pouca educação formal, ao entendimento da figura do gestor quase como um 'xerife' local, aquele que, após a chegada e presença efetiva do poder estatal, coíbe ou autoriza as práticas e usos dos elementos constituintes da paisagem

A criação e gestão de UCs acabam por revelar e ilustrar práticas políticas de hegemonia da ciência que escolhem o que e como proteger. As práticas legais de proteção da natureza acabam refletindo grupos sociais urbanos que valorizam $o$ conhecimento desenvolvido nas universidades e centros de pesquisa, sinônimo do moderno e do progresso, em detrimento dos valores e práticas tradicionais construídos empiricamente ao longo de gerações.

\section{REFERENCIAS}

AMADOR, A. B. O turismo e as transformações sócio-espaciais em Lumiar e São Pedro da Serra, Nova Friburgo - RJ. Monografia (Graduação em Geografia) - Rio de Janeiro: UFRJ. 1997.

ARAÚJO, J. R. A indústria em Nova Friburgo. In: ARAÚJO, J. R. e MAYER, J. M. (Coord.) Teia Serrana: formação histórica de Nova Friburgo. Rio de Janeiro: Editora ao livro técnico, 2003.

BARDIN, L. Análise de conteúdo. Lisboa: Edições 70, 2011.

BERNARDI, I.; SILVA L. R.; FALCO, P.; PIRES, J. S. R.; SANTOS, A. C. A. Análise comparativa das ferramentas de gestão: Plano de Manejo da APA Itupararanga e os Planos Diretores Municipais. Sociedade \& Natureza, v.32, p. 7591, 2019. https://doi.org/10.14393/SN-v32-202036541

BRASIL. Lei n ${ }^{\circ} 9.985$ de 18 de julho de 2000. Sistema Nacional de Unidades de Conservação. 
Available

in:

<http://www.planalto.gov.br/ccivil_03/leis/19985.h tm>. Acessed: March 11, 2020.

BÜSCHER, B., DRESSLER, W., FLETCHER, R. (Eds.) Nature Inc.: environmental conservation in the neoliberal age. Tucson: University of Arizona Press, 2014.

CARNEIRO, M. J.; BERTOLINO, V. F. A.; BERTOLINO, L. C. Agricultores e território: práticas e saberes. Rio de Janeiro: Trasso Comunicação/CNPq/Faperj, 2010.

CASTO JUNIOR, E.; COUTINHO, B. H.; FREITAS, L. E. Gestão da biodiversidade e áreas protegidas. In: GUERRA, A. J. T.; COELHO, M. C. N. (Org.) Unidades de conservação: abordagens e características geográficas. Rio de Janeiro: Bertrand Brasil. 2009.

DAVENPORT, L.; RAO, M. A história da proteção: paradoxos do passado e desafios do futuro. In: Spergel, B. e Terborgh, J. (Org.) Tornando os parques eficientes: estratégias para conservação da natureza nos trópicos. Curitiba: Ed. da UFPR/ Fundação O Boticário, 2002.

DIEGUES, A. C. S. O mito moderno da natureza intocada. São Paulo: Hucitec, 2008. $6^{\text {a }}$ ed. Available in: <http://nupaub.fflch.usp.br/sites/nupaub.fflch.usp.b r/files/O\%20mito\%20moderno.compressed.pdf $>$.

Acessed: May 21, 2020.

HOEFLE, S. W. Além da sociedade-natureza com a mais-que-Geografia Humana: Por uma teoria transdisciplinar de ética ambiental e visão do mundo. In: SPOSITO, E. S.; SILVA, C. A.; SANT'ANNA NETO, J.; MELAZZO, E. V. (Org.) A Diversidade da Geografia Brasileira. Rio de Janeiro: Editora Consequência, 2016.

IBDF/FBCN. INSTITUTO BRASILEIRO DE DESENVOLVIMENTO FlORESTAL. Plano do Sistema de Unidades de Conservação do Brasil. Brasília: Instituto Brasileiro de Desenvolvimento Florestal / Fundação Brasileira para a Conservação da Natureza, 1979.

INEA. INSTITUTO ESTADUAL DO AMBIENTE. APA Estadual de Macaé de Cima: plano de manejo - análise da UC. Módulo III. Rio de Janeiro: INEA, 2014. Available in: <http://www.inea.rj.gov.br/cs/groups/public/docum ents/document/zwew/mdgz/ edisp/inea0083758.pd f>. Acessed: April 03, 2020.

LASCHEFSKI, K. A.; DUTRA C.; DOULA, S. M. A legislação ambiental como foco de conflitos: uma análise a partir das representações sociais da natureza dos pequenos agricultores em Minas Gerais, Brasil. Sociedade \& Natureza, v. 24, $\mathrm{n}^{\circ} 3$, p. 405-417, 2012. https://doi.org/10.1590/S198245132012000300003

LEFF, E. Ecologia, capital e cultura - a territorialização da racionalidade ambiental. Petrópolis: Vozes, 2009.
MANTOVANI, W. Relação homem e natureza: raízes do conflito. Gaia Scientia. v. 3, no 1, p. 310, 2009. Available in: <https://periodicos.ufpb.br/index.php/gaia/article/v iew/3337/2738>. Acessed: January 15, 2020.

MAPBIOMAS. Projeto MapBiomas - Coleção 4 da Série Anual de Mapas de Cobertura e Uso de Solo do Brasil. Available in: <https://mapbiomas.org/>. Acessed: June 30, 2020.

MATTOS, C. P. Psicossociologia do turismo: uma via para interpretar o turismo na Área de Proteção Ambiental de Macaé de Cima, Nova Friburgo, RJ, Brasil. Tese (Doutorado em Psicossociologia de Comunidades e Ecologia Social) - Rio de Janeiro: UFRJ. 2018. Available in: <http://pos.eicos.psicologia.ufrj.br/wpcontent/uploads/2018_tese_cristiane_passos.pdf> Acessed: May 16, 2020.

MAYER, J. M. A criação de Nova Friburgo. In: ARAÚJO, J. R. e MAYER, J. M. (Coord) Teia Serrana: formação histórica de Nova Friburgo. Rio de Janeiro: Editora ao livro técnico, 2003.

MEDEIROS, R. Evolução das tipologias e categorias de áreas protegidas no Brasil. Ambiente \& Sociedade, v. 9, $\mathrm{n}^{\circ}$. 1, p. 41-64, 2006. http://dx.doi.org/10.1590/S1414-753X2006000100003

MENDES, S. P. Implantação da APA Macaé de Cima: um confronto entre a função social da propriedade e o direito ao meio ambiente ecologicamente equilibrado. Anais do V Encontro nacional da ANPPAS. Florianópolis, SC; 2010. Available in: <http://www.anppas.org.br/encontro5/cd/artigos/G T16-640-642-20100903213802.pdf>. Acessed: May 15, 2020.

NICOULIN, M. A gênese de Nova Friburgo: emigração e colonização suíça no Brasil 18171827. Rio de Janeiro: Fundação Biblioteca Nacional. 1995.

OLIVEIRA, R. R. Sustentados pela floresta. In: RUA, J. Paisagem, espaço e sustentabilidades: uma perspectiva multidimensional da geografia. Rio de Janeiro: Editora PUC-RIO, 2007.

REGO, V. V. B. S. Mundos em Confronto: o desenvolvimento do capitalismo e a educação numa comunidade camponesa. Dissertação (Mestrado em Educação) - Rio de Janeiro: PUCRJ. 1988.

REGO, V. V. B. S. Paraísos perdidos ou preservados: os múltiplos sentidos da cidadania em áreas de proteção ambiental. Periferia, v. 1, no 2 , p. 92-113, 2009. https://doi.org/10.12957/periferia.2009.3430

RIBEIRO, W. C.; LOBATO, W. OLIVEIRA, L. M. L. P. R.; LIBERATO, R. C. A concepção de natureza na civilização ocidental e a crise ambiental. Revista da Casa da Geografia de Sobral, v. 14, no. 1, p. 7-16, 2012. Available in: $<$ https://rcgs.uvanet.br/index.php/RCGS/article/vie w/8>. Acessed: May 15, 2020. 
RIO DE JANEIRO, Governo do Estado. Decreto estadual 29.213 de 14 de setembro de 2001 . Available

<http://www.pesquisaatosdoexecutivo.rj.gov.br/Ho me/Detalhe/30156>. Acessed: April 20, 2020.

RIO DE JANEIRO, Governo do Estado. Lei 2.049 de 22 de dezembro de 1992. Available in: <http://alerjln1.alerj.rj.gov.br/CONTLEI.NSF/b24a 2da5a077847c032564f4005d4bf2/485fe39fc6e845 1e0325651b0068e926?OpenDocument\#: :text=DI SP\%C3\%95E\%20SOBRE\%20A\%20PROIBI\%C3 $\% 87 \%$ C3\%830\%20DE,Art.>. Acessed: May 14, 2008.

TEIXEIRA, V. L. Novos contornos ocupacionais no meio rural fluminense: um estudo sobre a pluriatividade entre agricultores familiares. Tese (Doutorado em Ciências Econômicas) - Campinas: UNICAMP. 2009. Available in: <http://repositorio.unicamp.br/bitstream/REPOSIP/ 285692/1/Teixeira_VanessaLopes_D.pdf>

Acessed: May 30, 2020.

VILLAS BOAS, G. H. Etnogeomorfologia da APA Macaé de Cima: um objetivo e dois saberes. Tese (Doutorado em Geografia) - Rio de Janeiro: UFRJ. 2017. Available

in: http://objdig.ufrj.br/16/teses/870383.pdf Acessed: May 26, 2020.

\section{CONTRIBUIÇÃO DOS AUTORES}

Guilherme Hissa Villas Boas elaborou o rascunho original, analisou os dados, escreveu os resultados e revisou o artigo. Cristiane Passos de Mattos elaborou o rascunho original, analisou os dados, escreveu os resultados e revisou o artigo. 